\title{
Article \\ Gadolinium and Polythiophene Functionalized Polyurea Polymer Dots as Fluoro-Magnetic Nanoprobes
}

\author{
Soner Karabacak ${ }^{1}\left(\mathbb{D}\right.$, Alagappan Palaniappan ${ }^{2}\left(\mathbb{D}\right.$, Tsang Siu Hon Tony ${ }^{3}$, Teo Hang Tong Edwin ${ }^{2,4}$, \\ Balázs Gulyás $5,6,7$, Parasuraman Padmanabhan $5,6, *$ (D) and Ümit Hakan Yildiz 1,8,9,*
}

1 Department of Chemistry, Izmir Institute of Technology, Urla 35430, Izmir, Turkey; sonerkarabacak@iyte.edu.tr

2 School of Materials Science and Engineering, Nanyang Technological University, Singapore 639798, Singapore; alps@ntu.edu.sg (A.P.); e-e-htteo@ntu.edu.sg (T.H.T.E.)

3 Temasek Laboratories@NTU, 50 Nanyang Avenue, Singapore 639798, Singapore; shtsang@ntu.edu.sg

4 School of Electrical and Electronic Engineering, Nanyang Technological University, Singapore 639798, Singapore

5 Lee Kong Chian School of Medicine, Nanyang Technological University, Singapore 636921, Singapore; balazs.gulyas@ntu.edu.sg

6 Cognitive Neuroimaging Centre, Nanyang Technological University, 59 Nanyang Drive, Singapore 636921, Singapore

7 Department of Clinical Neuroscience, Karolinska Institute, 17176 Stockholm, Sweden

8 Department of Polymer Science and Engineering, Izmir Institute of Technology, Urla 35430, Izmir, Turkey

9 Denge Kimya, Velimese Industrial Region St. Ergene, Corlu 59860, Tekirdag, Turkey

* Correspondence: ppadmanabhan@ntu.edu.sg (P.P.); hakanyildiz@iyte.edu.tr (Ü.H.Y.)

check for

updates

Citation: Karabacak, S.;

Palaniappan, A.; Tony, T.S.H.; Edwin, T.H.T.; Gulyás, B.; Padmanabhan, P.; Yildiz, Ü.H. Gadolinium and Polythiophene Functionalized Polyurea Polymer Dots as Fluoro-Magnetic Nanoprobes. Nanomaterials 2022, 12, 642. https:// doi.org/10.3390/nano12040642

Academic Editor: Antonios Kelarakis

Received: 19 December 2021

Accepted: 5 February 2022

Published: 14 February 2022

Publisher's Note: MDPI stays neutral with regard to jurisdictional claims in published maps and institutional affiliations.

Copyright: (C) 2022 by the authors. Licensee MDPI, Basel, Switzerland. This article is an open access article distributed under the terms and conditions of the Creative Commons Attribution (CC BY) license (https:// creativecommons.org/licenses/by/ $4.0 /)$.

\begin{abstract}
A rapid and one-pot synthesis of poly 3-thiopheneacetic acid (PTAA) functionalized polyurea polymer dots (Pdots) using polyethyleneimine and isophorone diisocyanate is reported. The one-pot mini-emulsion polymerization technique yielded Pdots with an average diameter of $\sim 20 \mathrm{~nm}$. The size, shape, and concentration of the surface functional groups could be controlled by altering the synthesis parameters such as ultrasonication time, concentration of the surfactant, and crosslinking agent, and the types of isocyanates utilized for the synthesis. Colloidal properties of Pdots were characterized using dynamic light scattering and zeta potential measurements. The spherical geometry of Pdots was confirmed by scanning electron microscopy. The Pdots were postfunctionalized by 1,4,7,10 tetraazacyclododecane-1,4,7,10-tetraacetic acid for chelating gadolinium nanoparticles $\left(\mathrm{Gd}^{3+}\right)$ that provide magnetic properties to the Pdots. Thus, the synthesized Pdots possess fluorescent and magnetic properties, imparted by PTAA and $\mathrm{Gd}^{3+}$, respectively. Fluorescence spectroscopy and microscopy revealed that the synthesized dual-functional $\mathrm{Gd}^{3+}$-Pdots exhibited detectable fluorescent signals even at lower concentrations. Magnetic levitation experiments indicated that the $\mathrm{Gd}^{3+}$-Pdots could be easily manipulated via an external magnetic field. These findings illustrate that the dua- functional $\mathrm{Gd}^{3+}$-Pdots could be potentially utilized as fluorescent reporters that can be magnetically manipulated for bioimaging applications.
\end{abstract}

Keywords: dual-functional reporters; PTAA; polymer dots; polyurea Pdots; mini-emulsion polymerization; magnetic manipulation; fluorescent reporters; bioimaging

\section{Introduction}

A wide range of probes for magnetic resonance imaging [1], X-ray computed tomography [2-4], positron emission tomography [5,6], and fluorescence imaging [7,8] have been explored to facilitate therapy and diagnosis. Over the recent years, emphasis has been laid on the development of probes with more than one functionality. Polymer dots, a class of fluorescence imaging probes with high fluorescence intensity, photostability, and high biocompatibility are one of the ideal candidates for the development of multifunctional probes $[9,10]$. Polymer dots based nanoprobes have revolutionized common 
practice in bioimaging [11-16], diagnostics, and therapeutic applications [17,18]. The major advantages of polymer dot nanoprobes are their superior photophysical properties and post-functionalization capabilities. Therefore, polymer dots enable imaging of a wide range of samples from single cell to more complex tissues and organs.

The current reports on polymer dots exhibit their potential for in-vitro and in-vivo imaging and diagnosis [19-21]. Single chain polymer dots in reduced diameter $(<10 \mathrm{~nm})$ have shown improved quantum yield, photostability, and colloidal stability [21-28] as compared to larger diameter polymer dots. Recently, Ozenler et al. demonstrated the use of single-chain polymer dots for differentiation of cancer and healthy cells in co-culture medium [29]. Though single chain polymer dots are expected to show unambiguous advantages in imaging, post-functionalization possibilities are still limited due to the small surface area. Considering the current requirements in clinical practice, bioimaging probes capable of rapid functionalization, bioconjugation, and multimodal imaging are of high priority [30]. Further, the multi-functional probes should be biocompatible and facilitate high-resolution bioimaging. Recently, dual-functional fluoro-magnetic reporters have gained significant research attention as they enable visualization of several biological processes [31].

In this study, a facile one-pot approach [32] for the synthesis of dual-functional fluoromagnetic polymer dots reporters is described. Poly 3-thiopheneacetic acid (PTAA) [33] fluorescent reporters are added to a mixture of polyethyleneimine (PEI), isophorone diisocyanate (IPDI) to yield PTAA functionalized polyurea polymer dots (Pdots) via a one -pot mini-emulsion technique. The adopted mini-emulsion technique enables precise control of size, shape, and concentration of the surface functional groups by varying the parameters such as ultrasonication time, concentration of the surfactant, and crosslinking agent, and the types of isocyanates utilized for the synthesis. The Pdots were post-functionalized by 1,4,7,10 tetraazacyclododecane-1,4,7,10-tetraacetic acid (DOTA) for chelating gadolinium nanoparticles $\left(\mathrm{Gd}^{3+}\right)$ that impart magnetic properties to the Pdots. Hence, the PTAA and $\mathrm{Gd}^{3+}$ serve as dual-functional fluorescent and magnetic reporters, respectively, for multimodal bioimaging. The optical and magnetic properties of the $\mathrm{Gd}^{3+}-$ Pdots characterized using fluorescence spectroscopy and a magnetic levitation system, reveal detectable fluorescent signals even at lower concentrations and facile manipulation by an external magnetic field. Thus, the proposed one-pot mini-emulsion synthesis approach could be utilized to synthesize dual-functional $\mathrm{Gd}^{3+}$-Pdots for high-resolution multimodal imaging of various biological samples.

\section{Materials and Methods}

Dual-functional $\mathrm{Gd}^{3+}$-Pdots were synthesized as shown in Scheme 1. Pdots were prepared via a one-pot mini-emulsion technique. IPDI $(0.21 \mathrm{~mL}, 1 \mathrm{mmol})$, PEI 25,000 $(1 \mathrm{~g}, 0.04 \mathrm{mmol})$, PTAA $(1.25 \mathrm{mg}$ in $250 \mu \mathrm{L}$ water, $\mathrm{pH}: 9)$, hexadecane $(114 \mu \mathrm{L}, 0.387 \mathrm{mmol})$, and sodium dodecyl sulfate (SDS) $(84 \mathrm{mg}, 0.294 \mathrm{mmol})$ in $10 \mathrm{~mL}$ DI water were added to a $50 \mathrm{~mL}$ round-bottom flask and stirred for $1 \mathrm{~h}$ at room temperature. The pre-emulsion solution was then ultrasonicated for $2 \mathrm{~min}$. After ultrasonication, the mixture was added to a $50 \mathrm{~mL}$ round-bottom flask, and the reaction mixture was refluxed at $60^{\circ} \mathrm{C}$ for $4 \mathrm{~h}$ and then cooled to room temperature to yield the Pdots solution.

DOTA-NHS (10 mg, $20 \mu \mathrm{mol})$ in $100 \mu \mathrm{L}$ phosphate-buffered saline (PBS) solution was added to $100 \mu \mathrm{L}$ of Pdots solution with a magnetic stirrer and stirred for 1 day. Then, gadolinium (III) chloride hexahydrate $\left(\mathrm{GdCl}_{3} \cdot 6 \mathrm{H}_{2} \mathrm{O}\right)(75 \mathrm{mg}, 0.2 \mathrm{mmol})$ was added to $2 \mathrm{~mL}$ citric acid monohydrate solution $(230 \mathrm{mg}, 0.6 \mathrm{mmol})$ and stirred for 3 days, followed by purification using a $12-14 \mathrm{kDa}$ dialysis tube and to remove excess $\mathrm{Gd}^{3+}$ in solution. Five cycles of dialysis (each cycle for $24 \mathrm{~h}$ ) were performed against a $0.05 \mathrm{M}$ citrate solution ( $200 \mathrm{~mL}$, pH: 7.4) to yield the dual-functional $\mathrm{Gd}^{3+}$-Pdots reporters. All the $\mathrm{pH}$ adjustments during the synthesis of $\mathrm{Gd}^{3+}$-Pdots were performed using $\mathrm{NaOH}$ and $\mathrm{HCl}$. 

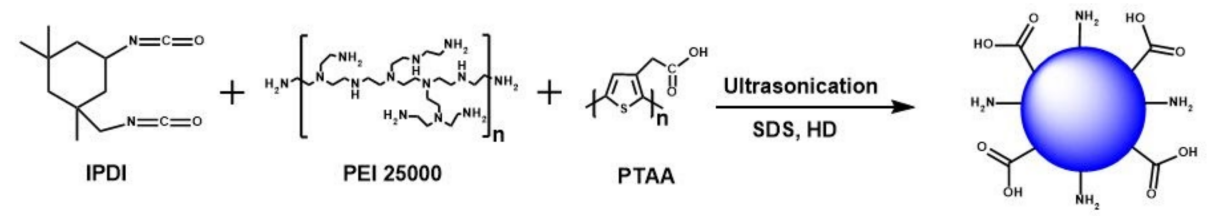

IPDI/PEI/PTAA Pdots
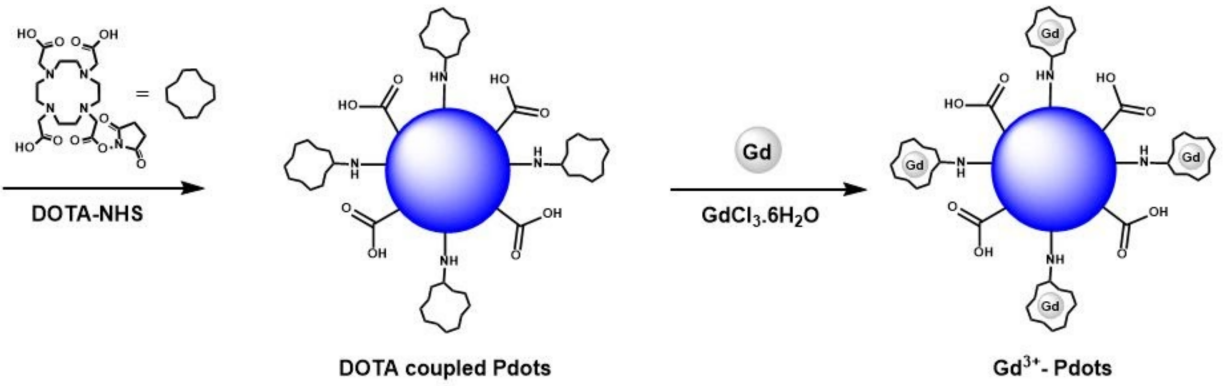

Scheme 1. Schematic representation of the preparation of $\mathrm{Gd}^{3+}-$ Pdots dual-functional reporters (Overall yield is $26.6 \%$ for $\mathrm{Gd}^{3+}$-Pdots dual-functional reporters).

\section{Results and Discussion}

Anionic PTAA was synthesized and characterized using NMR, UV-visible spectroscopy, and fluorescence spectroscopy to synthesize the Pdots fluorescence reporters. Firstly, poly 3-thiophene methyl acetate (PTMA) was characterized using ${ }^{1} \mathrm{H}$ NMR (Figure S1, $400 \mathrm{MHz}$, $\mathrm{CDCl}_{3}, \delta, \mathrm{ppm}$ ) that showed associated peaks at 7.30-7.00 (proton of thiophene ring, $\mathrm{m}$, $1 \mathrm{H}), 3.70$ (s, thiophene ring, $2 \mathrm{H}$ ), and 3.60 (s, methyl, $3 \mathrm{H})$. Then, FTIR-ATR spectroscopy was performed to compare PTMA and PTAA, as shown in Figure S2. It could be observed from Figure S2 that aromatic ester (C-O) functional group was observed in PTMA spectrum at $1310 \mathrm{~cm}^{-1}$ and $1270 \mathrm{~cm}^{-1}$ but not in the PTAA spectrum. This difference plays a key role in the characterization of PTAA. The most significant peak of the spectrum is the broad O-H peak observed in the $3400-2400 \mathrm{~cm}^{-1}$ range. Moreover, the carbonyl peak at $1700 \mathrm{~cm}^{-1}$ reveals the existence of the carboxyl group. The absorption peak at $3180-2980 \mathrm{~cm}^{-1}$ range refers to the $\mathrm{C}-\mathrm{H}$ bond on the ring of thiophene, and the aliphatic $\mathrm{C}-\mathrm{H}$ bond is observed at $2980-2780 \mathrm{~cm}^{-1}$ range.

UV-visible and fluorescence spectroscopy was carried out for PTAA at various $\mathrm{pH}$ to comprehend the $\mathrm{pH}$ sensitivity. The $\mathrm{pH}$ was adjusted between $\mathrm{pH} 3$ and 11 at room temperature. When the PTAA solution was prepared, $1 \mathrm{M} \mathrm{NaCl}$ was used for all samples to provide a constant ionic strength. As observed from Figure 1a, the solubility of PTAA increases with $\mathrm{pH}$, as revealed by the increase in absorbance intensity at maximum wavelength. A significant increase in UV maximum wavelength ( $\lambda$ maximum) is observed at $\mathrm{pH}$ range 5-6 as shown in Figure 1b, which demonstrates the conformational changes of PTAA. In addition, the fluorescence intensity decreases with $\mathrm{pH}$ (Figure 1c), as examined using $1.0 \mathrm{M} \mathrm{NaCl}$ solutions. As shown in Figure 1d, the maximum wavelength of the emission spectrum shows a significant increase at the $\mathrm{pH}$ range 5-6. These observations further indicate that PTAA exhibits good emission intensities (Figure 1c) around physiological $\mathrm{pH}$ ranges, making them an ideal candidate for the development of fluorescent reporters for bioimaging.

PTAA was then utilized as the fluorescence reporter to synthesize the Pdots using the one-pot mini-emulsion technique. SEM imaging of 1000 fold diluted Pdots reveals their spherical morphology (Figure 2a). Figure $2 \mathrm{~b}$ shows fluorescence microscopy (FM) imaging of Pdots confirming spherical geometry in solution. The particle size of Pdots measured using DLS analysis indicates an average hydrodynamic radius of $\sim 20 \mathrm{~nm}$, as shown in Figure 2c, which agrees with SEM imaging. Pdots analyzed via FTIR-ATR spectroscopy (Figure 2d) yielded a broad band spanning from 3600 to $3000 \mathrm{~cm}^{-1}$, which is attributed to the carboxylic acid - $\mathrm{OH}$ groups in the PTAA structure. The peaks associated with 
the carboxylic acid ( $\mathrm{C}=\mathrm{O}$ stretching mode of carboxyl group) is observed at $1715 \mathrm{~cm}^{-1}$ (deconvoluted spectrum is shown in dotted lines). The $\mathrm{NH}_{2}$ deformation mode peak is observed at $1636 \mathrm{~cm}^{-1}$, indicating that the surface of Pdots contains both $\mathrm{COOH}$ and $\mathrm{NH}_{2}$ groups. These characterization results illustrate successful synthesis of fluorescent Pdots.

a)
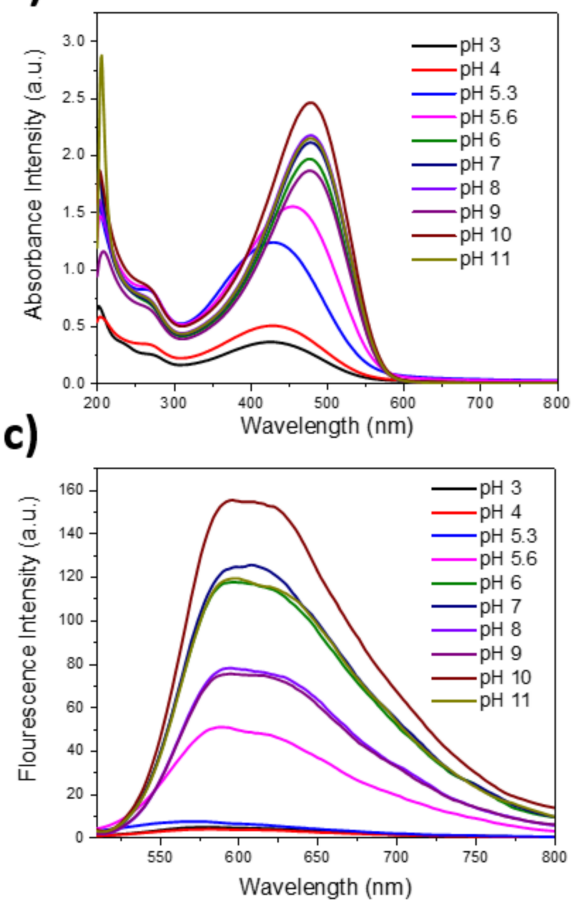

b)

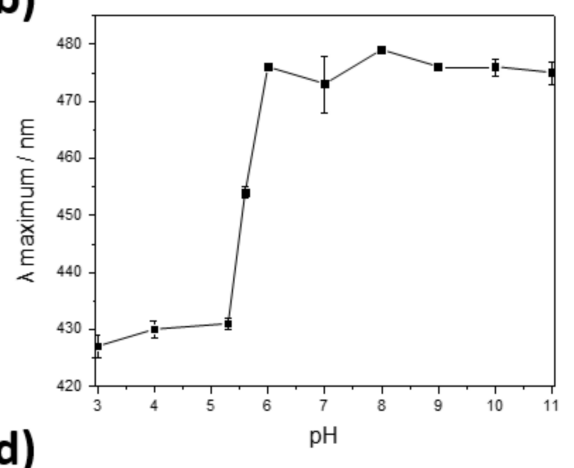

d)

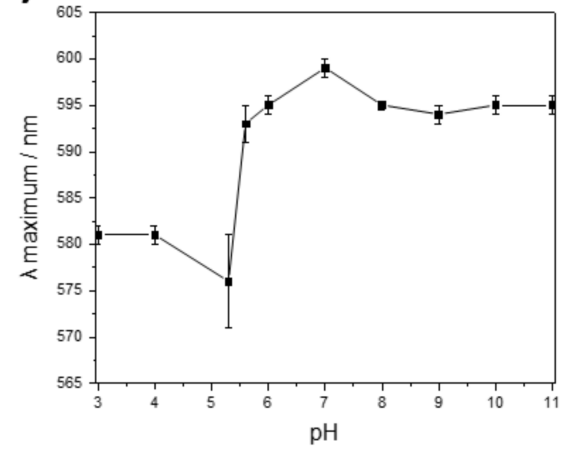

Figure 1. Optical characterization of PTAA (a) UV-visible spectrum of PTAA aqueous solution with $1.0 \mathrm{M} \mathrm{NaCl}$ concentrations at $\mathrm{pH}$ from 3 to 11 (b) UV-visible spectrum maximum wavelengths of PTAA at different $\mathrm{pH}$ (c) fluorescence spectrum of PTAA aqueous solution with $1.0 \mathrm{M} \mathrm{NaCl}$ concentrations at $\mathrm{pH}$ from 3 to 11 (d) fluorescence spectrum maximum wavelengths of PTAA at in different $\mathrm{pH}$.

Upon successful characterization of Pdots, a post-functionalization process was carried out to conjugate $\mathrm{Gd}^{3+}$ to impart magnetic properties to the Pdots. The Pdots prior and after $\mathrm{Gd}^{3+}$ functionalization were analyzed by fluorescence spectroscopy shown in Figure 3 (excited at $475 \mathrm{~nm}$ ), which yielded a broad emission spectrum with a peak maximum at $570 \mathrm{~nm}$. The fluorescence intensity of Pdots and $\mathrm{Gd}^{3+}-$ Pdots were found to be identical, which ascertains negligible interference of $\mathrm{Gd}^{3+}$ functionalization on the optical properties of PTAA. The slight shift in the emission maximum could be attributed to the change in the chemical environment of Pdots by $\mathrm{Gd}^{3+}$ cations. The colloidal properties of Pdots and $\mathrm{Gd}^{3+}$-Pdots were then characterized by Zeta potential measurements, which further confirmed $\mathrm{Gd}^{3+}$ post-functionalization process. Prior to the functionalization of DOTA and $\mathrm{Gd}^{3+}$ chelation, higher concentrations of $\mathrm{COO}^{-}$groups were available on Pdots, whereas the $\mathrm{COO}^{-}$groups were consumed after functionalization. The zeta potential of 11.8 and $6.10 \mathrm{mV}$ was measured for Pdots prior and after $\mathrm{Gd}^{3+}$ functionalization. The change in zeta potential was attributed to the reaction between primary amine groups and DOTA, thus, the decrement shows the binding of DOTA to the Pdots. The mobility of dual-functional reporters decreases with the functionalization of $\mathrm{Gd}^{3+}$ on Pdots because the size of the dual-functional reporters is larger than Pdots. Additionally, no significant difference was observed for the conductivity prior and after $\mathrm{Gd}^{3+}$ functionalization, as shown in Table 1 , indicating that $\mathrm{Gd}^{3+}$-Pdots solution does not contain free $\mathrm{Gd}^{3+}$ ions. 
a)

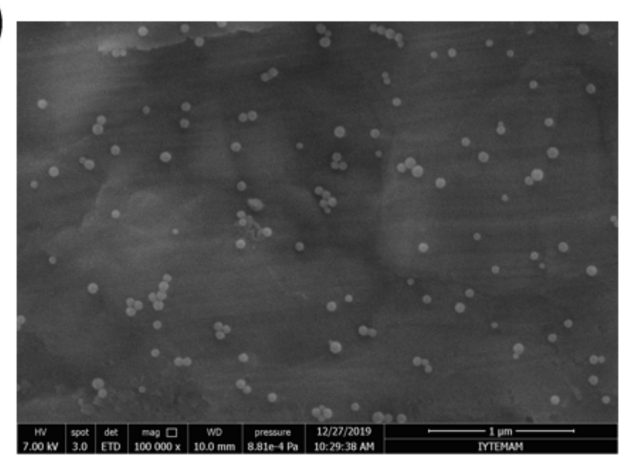

c)

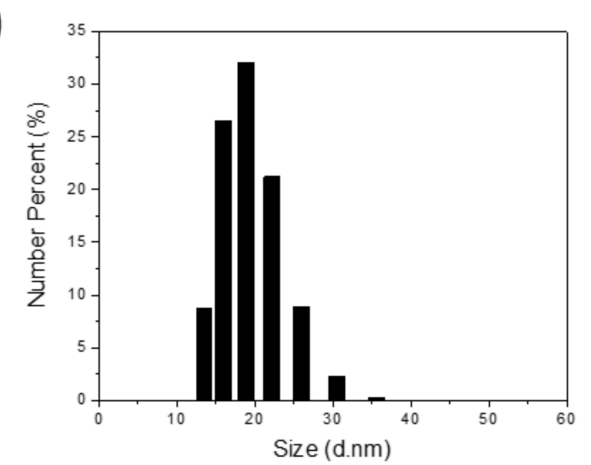

b)

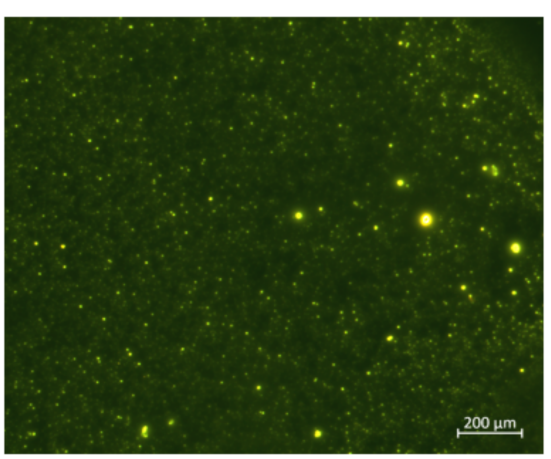

d)

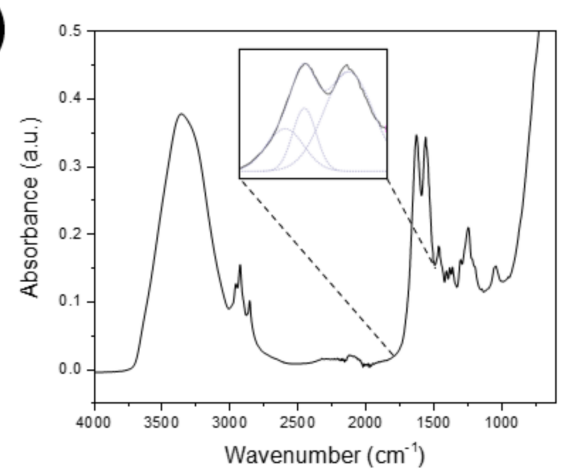

Figure 2. (a) SEM image of Pdots. (b) FM image of Pdots (c) particle size analysis of Pdots (d) FTIRATR spectrum of Pdots.

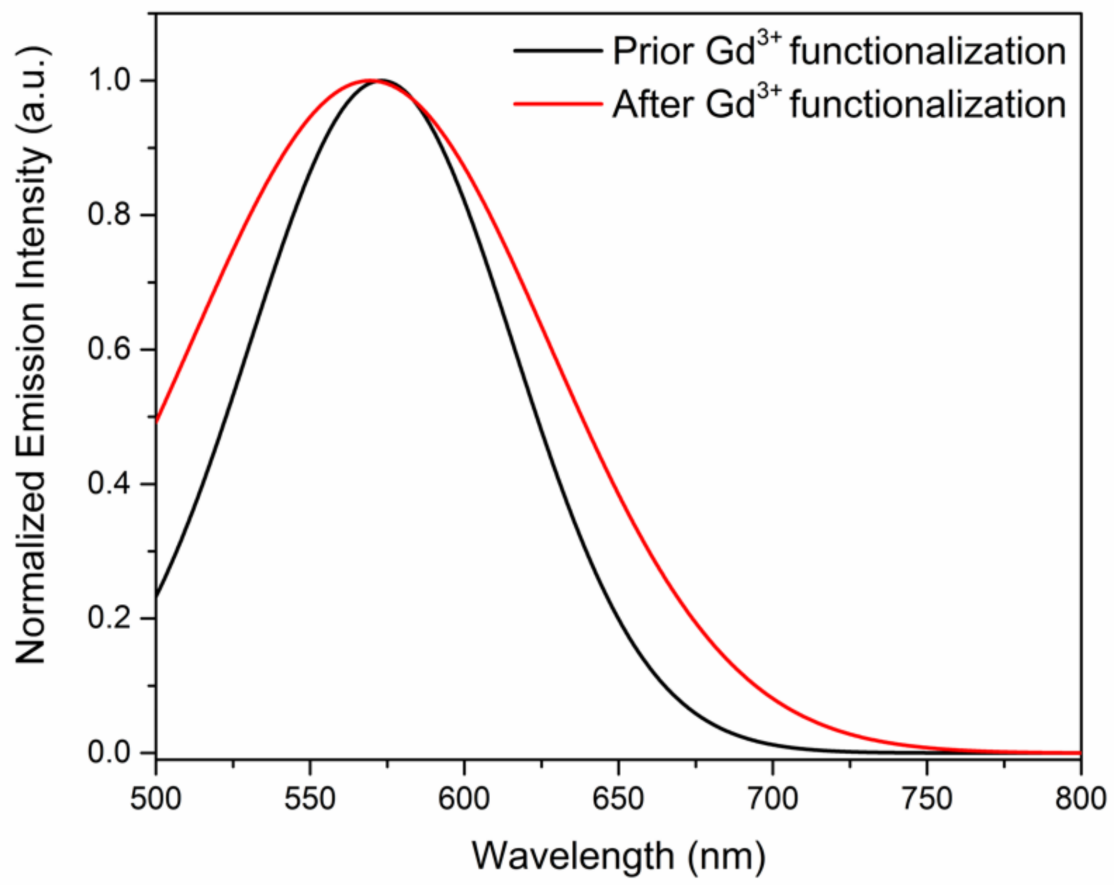

Figure 3. Emission spectrum of Pdots prior and after $\mathrm{Gd}^{3+}$ functionalization, respectively. 
Table 1. Zeta potential measurements of Pdots and $\mathrm{Gd}^{3+}$-Pdots.

\begin{tabular}{|c|c|c|c|}
\hline Sample & $\begin{array}{c}\text { Zeta Potential } \\
(\mathrm{mV})\end{array}$ & $\begin{array}{c}\text { Mobility } \\
(\mu \mathrm{mcm} / \mathrm{Vs})\end{array}$ & $\begin{array}{l}\text { Conductivity } \\
(\mathrm{mS} / \mathrm{cm})\end{array}$ \\
\hline Pdots & $11.8 \pm 0.60$ & $0.922 \pm 0.048$ & 0.104 \\
\hline $\mathrm{Gd}^{3+}$-Pdots & $6.10 \pm 1.10$ & $0.478 \pm 0.086$ & 0.106 \\
\hline
\end{tabular}

The $\mathrm{Gd}^{3+}$ chelation provides magnetic properties to Pdots, enabling magnetic manipulation of as well as magnetic levitation of Pdots. As shown in Figure 4a, the customized magnetic levitation system is fabricated using a glass capillary filled with $\mathrm{Gd}^{3+}$-Pdots solution and sandwiched between two magnets, where the same poles are positioned against each other. Polystyrene beads are utilized to illustrate the magnetic properties of $\mathrm{Gd}^{3+}$-Pdots. As schematically illustrated in Figure 4a, in the absence of magnets, the polystyrene beads rest at the bottom of the glass capillary since they have a higher density than $\mathrm{Gd}^{3+}$-Pdots solution filled in capillary, whereas they levitate at a certain height from the bottom of the glass capillary in the presence of the magnets. Figure $4 b, c$ shows the fluorescence and optical microscope images of the levitating polystyrene beads (polystyrene beads with a density $=1.08 \mathrm{~g} / \mathrm{mL}$ ) in the presence of a magnet. The levitation of polystyrene beads is due to the effect of the paramagnetic behavior of $\mathrm{Gd}^{3+}$-Pdots, where $\mathrm{F}_{\text {buoyancy }}{ }^{+}$ $\mathrm{F}_{\text {magnetic }}>\mathrm{F}_{\text {gravitation }}$.

In addition, the manipulation of $\mathrm{Gd}^{3+}-$ Pdots reporters was tested by using a neodymium bar magnet. As observed from Figure $5 b$, the $\mathrm{Gd}^{3+}$-Pdots reporters are scattered in the solution, whereas they assemble and cover the surface of the magnet placed under the petri dish after a time period of $24 \mathrm{~h}$ (Figure 5c, also schematically represented in Figure 5a). This observation shows that dual-functional $\mathrm{Gd}^{3+}$-Pdots reporters could be manipulated by an external magnetic field and that the magnetic patterning and assembly on samples are feasible owing to their intrinsic magnetic properties. These results ascertain that the synthesized $\mathrm{Gd}^{3+}$-Pdots could serve as dual-functional fluoro-magnetic nanoprobes for bioimaging.

a)

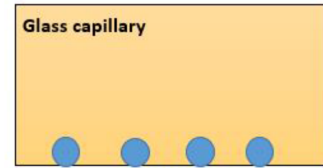

b)

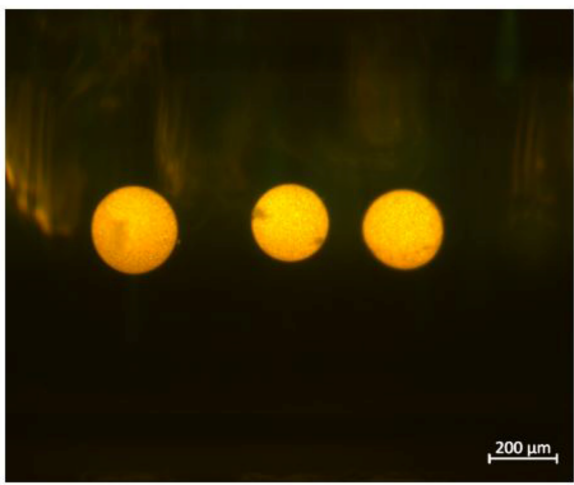

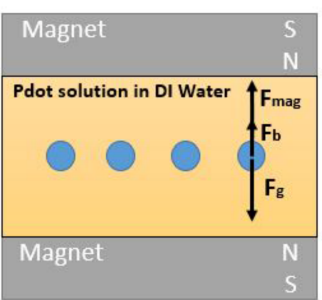

c)

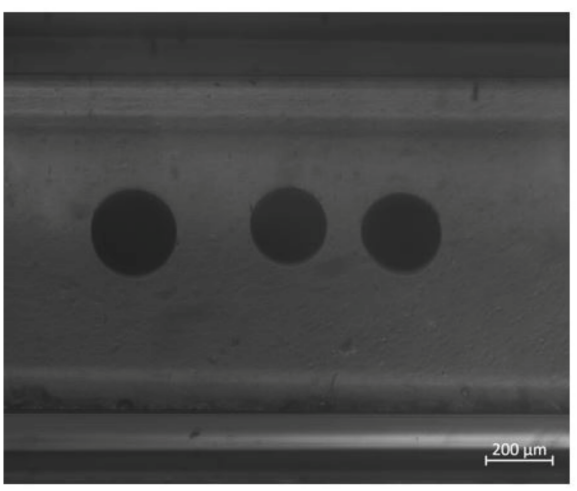

Figure 4. (a) Schematic illustration of the magnetic levitation system (b) fluorescence and (c) optical images of the polystyrene beads in the presence of magnets. 
a)

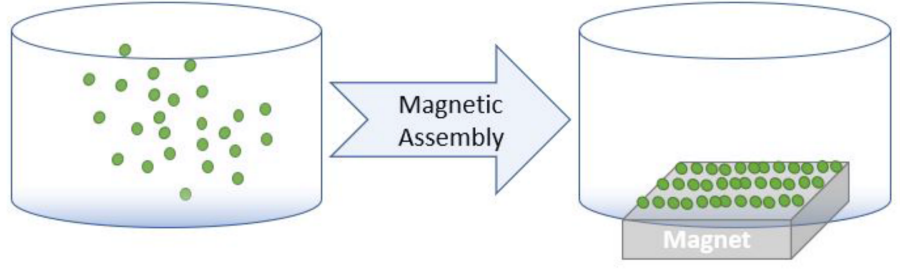

b)

c)
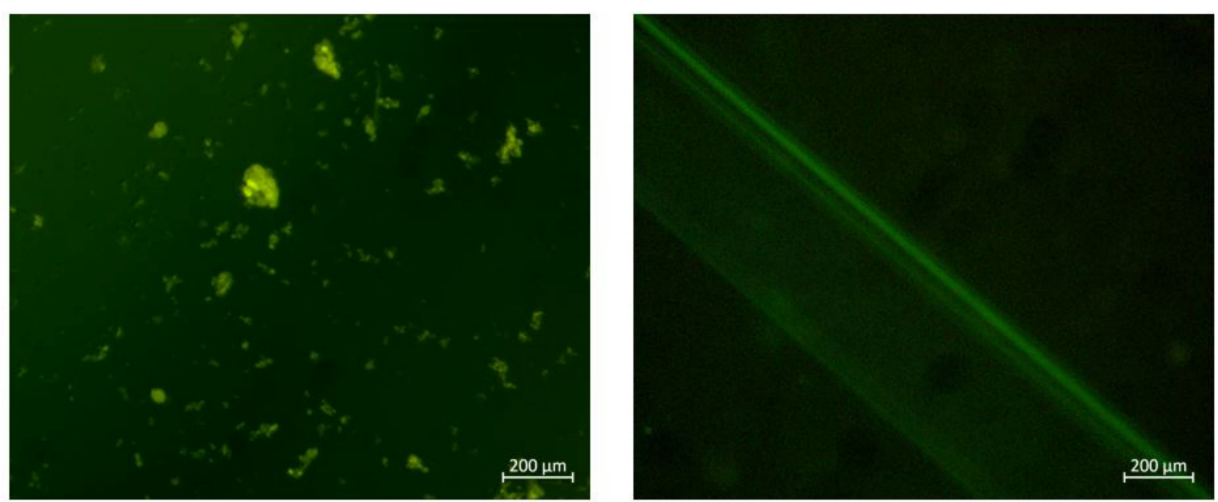

Figure 5. (a) Schematic representation of assembly of $\mathrm{Gd}^{3+}-$ Pdots on the surface of the magnet (b) scattering of $\mathrm{Gd}^{3+}$-Pdots reporters in the absence of magnets and (c) assembly of $\mathrm{Gd}^{3+}$-Pdots reporters along the surface of the magnet after a time period of $24 \mathrm{~h}$.

\section{Conclusions}

In conclusion, dual-functional $\mathrm{Gd}^{3+}$-Pdot reporters were successfully synthesized via a one-pot mini-emulsion technique for bioimaging applications. SEM, fluorescence microscopy, UV-visible and fluorescence spectroscopy, and magnetic levitation characterization results illustrated that the $\mathrm{Gd}^{3+}$-Pdot reporters possess fluorescence and magnetic properties, imparted by PTAA and $\mathrm{Gd}^{3+}$, respectively. Thus, the synthesized reporters could be utilized for multimodal bioimaging applications. Furthermore, with the postfunctionalization of $\mathrm{Gd}^{3+}$, the Pdots could be magnetically manipulated via an external magnetic field. Apart from bioimaging, we foresee that the dual-functional $\mathrm{Gd}^{3+}-\mathrm{Pdot}$ reporters could be utilized as magnetic tweezers for manipulating micron sized objects.

Supplementary Materials: The following supporting information can be downloaded at: https: / / www.mdpi.com/article/10.3390/nano12040642/s1, Figure S1: ${ }^{1}$ H NMR spectrum of poly (3thiophene methyl acetate); Figure S2: FTIR-ATR spectrum of poly (3-thiophene methyl acetate) (PTMA) and polythiophene acetic acid (PTAA); Figure S3: Purification of $\mathrm{Gd}^{3+}$-Pdots from free Gadolinium.

Author Contributions: Conceptualization, S.K., Ü.H.Y., A.P., T.S.H.T., T.H.T.E., B.G. and P.P.; methodology, S.K.; formal analysis, S.K. and Ü.H.Y.; investigation, S.K.; resources, Ü.H.Y.; data curation, S.K.; writing—original draft preparation, S.K, Ü.H.Y., A.P. and P.P.; writing-review and editing, S.K., S.K., Ü.H.Y., A.P., T.S.H.T., T.H.T.E., B.G. and P.P.; visualization, S.K.; supervision, Ü.H.Y.; project administration, Ü.H.Y.; funding acquisition, Ü.H.Y.; A.P., T.S.H.T., T.H.T.E., B.G. and P.P. All authors have read and agreed to the published version of the manuscript.

Funding: This work was supported by The Scientific and Technological Research Council of Turkey, TUBITAK Projects $116 Z 547$ and 120Z588. Author S.K. is YOK 100-2000 scholarship holder.

Institutional Review Board Statement: Not applicable.

Informed Consent Statement: Not applicable.

Data Availability Statement: The raw/processed data required to reproduce these findings cannot be shared at this time as the data also forms part of an ongoing study. 
Acknowledgments: We are grateful to Ahu Arslan Yildız for enabling us to benefit from the laboratory facilities and Fatih Özefe for his assistance with magnetic levitation equipment. The authors B.G. and P.P. would also like to acknowledge Imaging Probe Development Platform (IPDP) and the support from the Cognitive Neuro Imaging Centre (CONIC) at NTU.

Conflicts of Interest: The authors declare no conflict of interest.

\section{References}

1. Carril, M. Activatable probes for diagnosis and biomarker detection by MRI. J. Mater. Chem. B 2017, 5, 4332-4347. [CrossRef] [PubMed]

2. Lusic, H.; Grinstaff, M.W. X-ray-computed tomography contrast agents. Chem. Rev. 2013, 113, 1641-1666. [CrossRef]

3. DeKrafft, K.E.; Xie, Z.; Cao, G.; Tran, S.; Ma, L.; Zhou, O.Z.; Lin, W. Iodinated nanoscale coordination polymers as potential contrast agents for computed tomography. Angew. Chem. 2009, 121, 10085-10088. [CrossRef]

4. Liu, Y.; Ai, K.; Lu, L. Nanoparticulate X-ray computed tomography contrast agents: From design validation to in vivo applications. Acc. Chem. Res. 2012, 45, 1817-1827. [CrossRef]

5. Goel, S.; England, C.G.; Chen, F.; Cai, W. Positron emission tomography and nanotechnology: A dynamic duo for cancer theranostics. Adv. Drug Deliv. Rev. 2017, 113, 157-176. [CrossRef] [PubMed]

6. Schuster, D.M.; Nieh, P.T.; Jani, A.B.; Amzat, R.; Bowman, F.D.; Halkar, R.K.; Master, V.A.; Nye, J.A.; Odewole, O.A.; Osunkoya, A.O. Anti-3-[18F] FACBC positron emission tomography-computerized tomography and 111In-capromab pendetide single photon emission computerized tomography-computerized tomography for recurrent prostate carcinoma: Results of a prospective clinical trial. J. Urol. 2014, 191, 1446-1453. [CrossRef]

7. Wu, C.; Bull, B.; Szymanski, C.; Christensen, K.; McNeill, J. Multicolor conjugated polymer dots for biological fluorescence imaging. ACS Nano 2008, 2, 2415-2423. [CrossRef]

8. Li, K.; Liu, B. Polymer-encapsulated organic nanoparticles for fluorescence and photoacoustic imaging. Chem. Soc. Rev. 2014, 43, 6570-6597. [CrossRef]

9. Zhu, C.; Liu, L.; Yang, Q.; Lv, F.; Wang, S. Water-soluble conjugated polymers for imaging, diagnosis, and therapy. Chem. Rev. 2012, 112, 4687-4735. [CrossRef]

10. Wang, Y.; Feng, L.; Wang, S. Conjugated polymer nanoparticles for imaging, cell activity regulation, and therapy. Adv. Funct. Mater. 2019, 29, 1806818. [CrossRef]

11. Kuo, C.-T.; Thompson, A.M.; Gallina, M.E.; Ye, F.; Johnson, E.S.; Sun, W.; Zhao, M.; Yu, J.; Wu, I.-C.; Fujimoto, B. Optical painting and fluorescence activated sorting of single adherent cells labelled with photoswitchable Pdots. Nat. Commun. 2016, 7, 11468. [CrossRef] [PubMed]

12. Pu, K.; Mei, J.; Jokerst, J.V.; Hong, G.; Antaris, A.L.; Chattopadhyay, N.; Shuhendler, A.J.; Kurosawa, T.; Zhou, Y.; Gambhir, S.S. Diketopyrrolopyrrole-based semiconducting polymer nanoparticles for in vivo photoacoustic imaging. Adv. Mater. 2015, 27, 5184-5190. [CrossRef] [PubMed]

13. Rong, Y.; Wu, C.; Yu, J.; Zhang, X.; Ye, F.; Zeigler, M.; Gallina, M.; Wu, I.; Zhang, Y.; Chan, Y.; et al. Multicolor Fluorescent Semiconducting Polymer Dots with Narrow Emissions and High Brightness. ACS Nano 2013, 7, 376-384. [CrossRef] [PubMed]

14. Yang, Y.; Chen, J.; Yang, Y.; Xie, Z.; Song, L.; Zhang, P.; Liu, C.; Liu, J. A 1064 nm excitable semiconducting polymer nanoparticle for photoacoustic imaging of gliomas. Nanoscale 2019, 11, 7754-7760. [CrossRef] [PubMed]

15. Yu, J.; Rong, Y.; Kuo, C.-T.; Zhou, X.-H.; Chiu, D.T. Recent advances in the development of highly luminescent semiconducting polymer dots and nanoparticles for biological imaging and medicine. Anal. Chem. 2017, 89, 42-56. [CrossRef]

16. Wu, C.; Schneider, T.; Zeigler, M.; Yu, J.; Schiro, P.G.; Burnham, D.R.; McNeill, J.D.; Chiu, D.T. Bioconjugation of ultrabright semiconducting polymer dots for specific cellular targeting. J. Am. Chem. Soc. 2010, 132, 15410-15417. [CrossRef]

17. Moon, J.H.; MacLean, P.; McDaniel, W.; Hancock, L.F. Conjugated polymer nanoparticles for biochemical protein kinase assay. Chem. Commun. 2007, 46, 4910-4912. [CrossRef]

18. Sun, K.; Tang, Y.; Li, Q.; Yin, S.; Qin, W.; Yu, J.; Chiu, D.T.; Liu, Y.; Yuan, Z.; Zhang, X. In vivo dynamic monitoring of small molecules with implantable polymer-dot transducer. ACS Nano 2016, 10, 6769-6781. [CrossRef]

19. Hu, D.; Yu, J.; Padmanaban, G.; Ramakrishnan, S.; Barbara, P.F. Spatial confinement of exciton transfer and the role of conformational order in organic nanoparticles. Nano Lett. 2002, 2, 1121-1124. [CrossRef]

20. Eder, T.; Stangl, T.; Gmelch, M.; Remmerssen, K.; Laux, D.; Höger, S.; Lupton, J.M.; Vogelsang, J. Switching between H-and J-type electronic coupling in single conjugated polymer aggregates. Nat. Commun. 2017, 8, 1641. [CrossRef]

21. Feng, L.; Zhu, C.; Yuan, H.; Liu, L.; Lv, F.; Wang, S. Conjugated polymer nanoparticles: Preparation, properties, functionalization and biological applications. Chem. Soc. Rev. 2013, 42, 6620-6633. [CrossRef] [PubMed]

22. Tuncel, D.; Demir, H.V. Conjugated polymer nanoparticles. Nanoscale 2010, 2, 484-494. [CrossRef] [PubMed]

23. Grey, J.K.; Kim, D.Y.; Norris, B.C.; Miller, W.L.; Barbara, P.F. Size-dependent spectroscopic properties of conjugated polymer nanoparticles. J. Phys. Chem. B 2006, 110, 25568-25572. [CrossRef] [PubMed]

24. Yu, J.; Wu, C.; Zhang, X.; Ye, F.; Gallina, M.E.; Rong, Y.; Wu, I.C.; Sun, W.; Chan, Y.H.; Chiu, D.T. Stable functionalization of small semiconducting polymer dots via covalent cross-linking and their application for specific cellular Imaging. Adv. Mater. 2012, 24, 3498-3504. [CrossRef] [PubMed] 
25. Sun, K.; Chen, H.; Wang, L.; Yin, S.; Wang, H.; Xu, G.; Chen, D.; Zhang, X.; Wu, C.; Qin, W. Size-dependent property and cell labeling of semiconducting polymer dots. ACS Appl. Mater. Interfaces 2014, 6, 10802-10812. [CrossRef]

26. Wu, L.; Wu, I.-C.; DuFort, C.C.; Carlson, M.A.; Wu, X.; Chen, L.; Kuo, C.-T.; Qin, Y.; Yu, J.; Hingorani, S.R. Photostable ratiometric pdot probe for in vitro and in vivo imaging of hypochlorous acid. J. Am. Chem. Soc. 2017, 139, 6911-6918. [CrossRef]

27. Wang, B.; Lu, S. The light of carbon dots: From mechanism to applications. Matter 2022, 5, 110-149. [CrossRef]

28. Yang, X.; Sui, L.; Wang, B.; Zhang, Y.; Tang, Z.; Yang, B.; Lu, S. Red-emitting, self-oxidizing carbon dots for the preparation of white LEDs with super-high color rendering index. Sci. China Chem. 2021, 64, 1547-1553. [CrossRef]

29. Özenler, S.; Yucel, M.; Tüncel, O.z.; Kaya, H.; Özçelik, S.; Yildiz, U.H. Single chain cationic polymer dot as a fluorescent probe for cell imaging and selective determination of hepatocellular carcinoma cells. Anal. Chem. 2019, 91, 10357-10360. [CrossRef]

30. Thiruppathi, R.; Mishra, S.; Ganapathy, M.; Padmanabhan, P.; Gulyás, B. Nanoparticle functionalization and its potentials for molecular imaging. Adv. Sci. 2017, 4, 1600279. [CrossRef]

31. Li, K.; Ding, D.; Huo, D.; Pu, K.Y.; Thao, N.N.P.; Hu, Y.; Li, Z.; Liu, B. Conjugated polymer based nanoparticles as dual-modal probes for targeted in vivo fluorescence and magnetic resonance imaging. Adv. Funct. Mater. 2012, 22, 3107-3115. [CrossRef]

32. Barrère, M.; Landfester, K. High molecular weight polyurethane and polymer hybrid particles in aqueous miniemulsion. Macromolecules 2003, 36, 5119-5125. [CrossRef]

33. Kim, B.; Chen, L.; Gong, J.; Osada, Y. Titration behavior and spectral transitions of water-soluble polythiophene carboxylic acids. Macromolecules 1999, 32, 3964-3969. [CrossRef] 